\title{
Bent Singlet Cyclobutylcarbene: Computed Geometry, Properties, and Product Selectivity of a Nonclassical Carbene
}

Murray G. Rosenberg ${ }^{\S}$ and Udo H. Brinker ${ }^{*},+\S$

${ }^{\dagger}$ Institute of Organic Chemistry, University of Vienna, Währinger Strasse 38, A-1090 Vienna, Austria

§Department of Chemistry, The State University of New York at Binghamton, P. O. Box 6000, Binghamton, NY, 13902-6000, United States

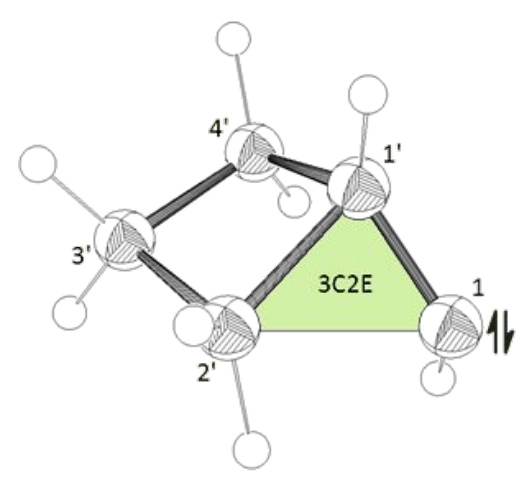

\section{SUPPORTING INFORMATION}




\section{PuRPorted Syntheses of CyClobutylCARBene (1) $)^{\mathrm{S1}-\mathrm{S4}}$}

Scheme S1. Possible Formation of 1 under Wurtz Coupling Reaction Conditions ${ }^{a}$

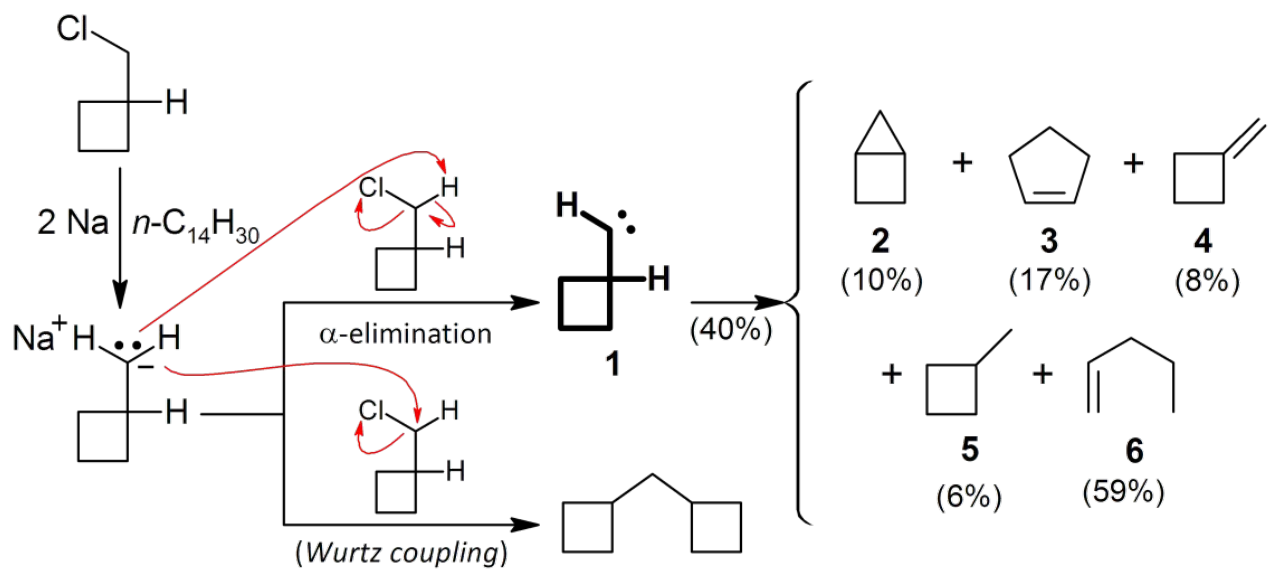

${ }^{a}$ cf. Ref. S1.

Scheme S2. Possible Formation of 1 under in situ Bamford-Stevens Reaction Conditions ${ }^{a}$

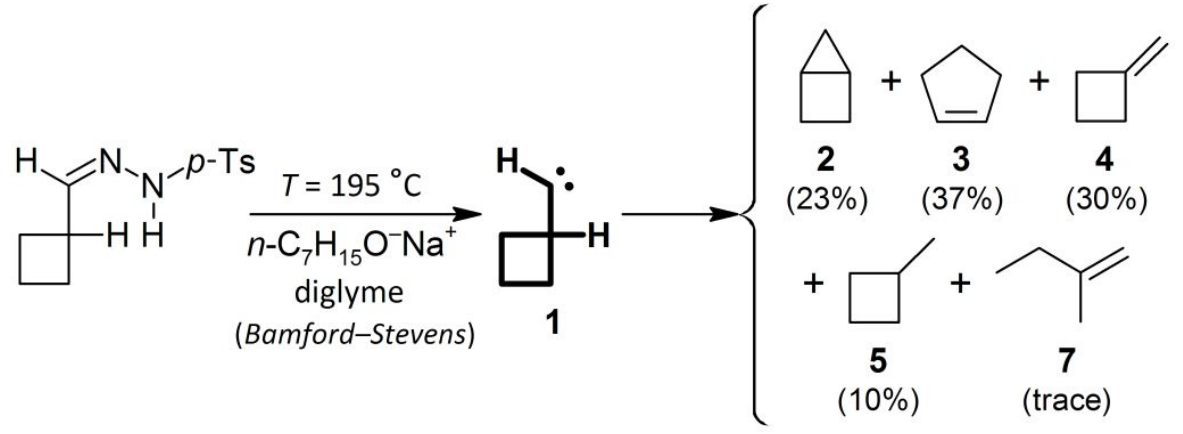

${ }^{a}$ cf. Ref. S2.

Scheme S3. Possible Formation of 1 under Photolytic Reaction Conditions ${ }^{a, b}$

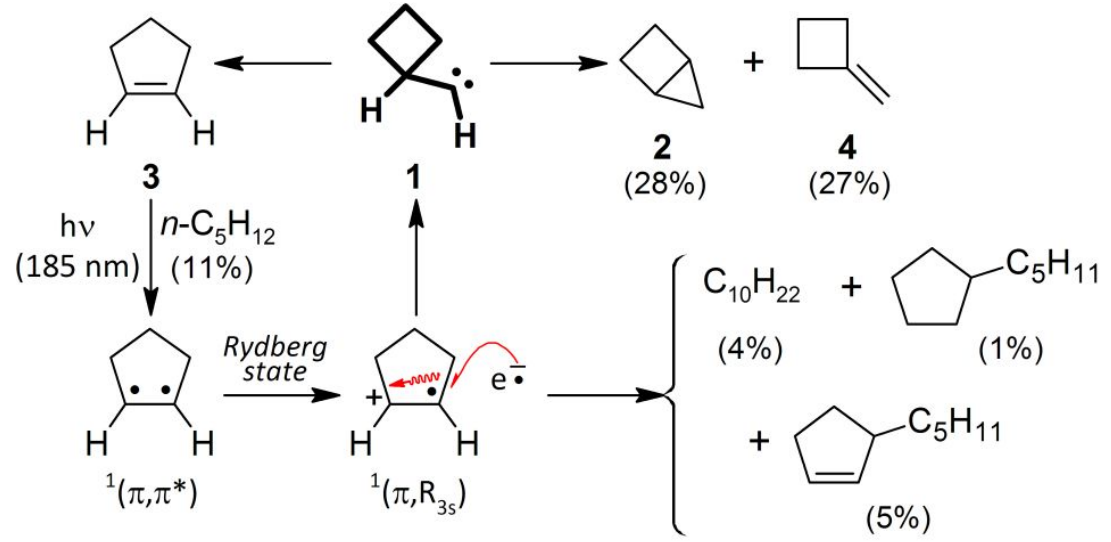

${ }^{a}$ cf. Ref. S3. ${ }^{b}$ cf. Ref. S4. 


\section{Computational Modeling}

Computational Methods. Quantum chemical calculations were performed using the Spartan'14 Parallel Suite (v. 1.1.8) computer program. ${ }^{55}$ Unrestricted Hartree-Fock (UHF) wave functions of the molecules and transition states were corrected for electron-electron correlation using Møller-Plesset perturbation theory. Second-order UMP2(full) was used for geometry optimizations and frequency calculations. Frozen-core fourth-order M $\varnothing$ ller-Plesset perturbation theory UMP4(fc) was used for single-point energy calculations. Use of the more costly UMP4(full) method was unwarranted because the difference in final energies between UMP4(fc) and UMP4(full) was negligible.

The equilibrium geometries of the gas-phase molecules were obtained using the UMP2(full)/6-311++G(d,p) theoretical model. Normal-mode vibrational analyses were performed at the level of geometry optimization. The harmonic frequencies were used to obtain temperature-independent zero-point vibrational energy $\left(E_{\text {ZPVE }}\right)^{56}$ and temperaturedependent thermal vibrational energy $\left(\Delta_{\text {vib }} H\right)$ values. Each TS had one and only one normal mode with an imaginary frequency $\left(\bar{v}_{\mathrm{TS}}\right)$. Intrinsic reaction coordinates (IRC)s were generated to follow the transformation of reaction intermediate to product using the UM06-2X/6-31+G(d) theoretical model. ${ }^{\mathrm{S}}$

Single-point energy $(E)$ values were computed using the UMP4(fc)/6-311++G(2df,2p) theoretical model. All $E_{\mathrm{ZPVE}}$ values were scaled by $\mathrm{z}=0.95$ before being added to $E(T=0 \mathrm{~K} ; p=$ $0 \mathrm{~atm})$. Relative energy values $\left(\Delta_{\mathrm{rel}} E\right)$ are specified with regard to a reference molecule, which was set equal to [0] $\mathrm{kcal} / \mathrm{mol}$. Conversion of $E$ values to enthalpy $\left(H_{T}\right)$ values was done according to eq S1 (computational standard-state: $T=298.15 \mathrm{~K} ; p=1 \mathrm{~atm}$; Table S1). All $\Delta_{\text {vib }} H$ values were scaled by $\mathrm{H}=0.95$ before being added to the ZPVE-corrected $E$ values. The increase in kinetic energy, due to translations $(3(1 / 2) R T)$ and rotations $(3(1 / 2) R T)$, for each nonlinear molecule was then added. Finally, $R T$ (i.e., " $p V$ work" needed to expand one mole of ideal gas to $V=24.465 \mathrm{~L}$ at $T=298.15 \mathrm{~K}$ and $p=1 \mathrm{~atm}$ ) was added to obtain $H_{T}$ (eq S1).

\section{Table S1. Values Used in Computations with Equation S1}

\begin{aligned} \hline Parameter & Value \\ \hline$V & =n R T / p \\ & =24.465 \mathrm{~L} \\ p & =1 \mathrm{~atm} \\ n & =1 \mathrm{~mol} \\ \mathrm{R} & =1.9872 \times 10^{-3}(\mathrm{kcal} / \mathrm{mol}) / \mathrm{K} \\ & =8.2057 \times 10^{-2}(\mathrm{~L} \cdot \mathrm{atm} / \mathrm{mol}) / \mathrm{K} \\ T & =298.15 \mathrm{~K}\end{aligned}$




$$
\begin{aligned}
\hline \text { Parameter } & \text { Value } \\
\hline \mathrm{RT} & =25^{\circ} \mathrm{C} \\
3(1 / 2) \mathrm{RT} & =0.592 \mathrm{kcal} / \mathrm{mol} \\
1 \text { hartree } & =627.589 \mathrm{kcal} / \mathrm{mol} \\
\hline H_{T} & =\left[E+\mathrm{Z}\left(E_{\mathrm{ZPVE}}\right)\right]+\mathrm{H}\left(H_{\text {vib }}\right)+(3(1 / 2) \mathrm{R} T)_{\text {translational }}+(3(1 / 2) \mathrm{mol} T)_{\text {rotational }}+(\mathrm{R} T)_{\text {ideal gas }}
\end{aligned}
$$

\section{EQUIVALENCY OF $\triangle \triangle E$ AND 2( $\Delta \chi)$}

$$
\begin{aligned}
\Delta \Delta E & =\left(E_{\pi^{*}}-E_{\sigma}\right)-\left(E_{\mathrm{p}}-E_{\pi}\right) \\
& =\left(E_{\pi^{*}}-E_{\sigma}\right)+\left(E_{\pi}-E_{\mathrm{p}}\right) \\
& =\left(E_{\pi^{*}}+E_{\pi}\right)_{\text {alkene }}-\left(E_{\mathrm{p}}+E_{\sigma}\right)_{\text {carbene }} \\
& =-\left(E_{\mathrm{p}}+E_{\sigma}\right)_{\text {carbene }}+\left(E_{\pi^{*}}+E_{\pi}\right)_{\text {alkene }} \\
& =2\left[(-1 / 2)\left(E_{\mathrm{p}}+E_{\sigma}\right)_{\text {carbene }}-(-1 / 2)\left(E_{\pi^{*}}+E_{\pi}\right)_{\text {alkene }}\right] \\
& =2\left(\chi_{\text {carbene }}-\chi_{\text {alkene }}\right) \\
& =2(\Delta \chi)
\end{aligned}
$$

\section{REFERENCES}

(S1) Richey, H. G., Jr.; Hill, E. A. Reaction of Cycloalkylmethyl Chlorides with Sodium. Fused Cyclopropanes from Cycloalkylcarbenes. J. Org. Chem. 1964, 29, 421-423.

(S2) Paskovich, D. H.; Kwok, P. W. N. The Thermal Decomposition of Cyclobutane Carboxaldehyde $p$-Tosylhydrazone. Tetrahedron Lett. 1967, 8, 2227-2231.

(S3) Inoue, Y.; Mukai, T.; Hakushi, T. Direct Photolysis at $185 \mathrm{~nm}$ of Cyclopentene and 2Norbornene. A Novel Reaction Channel for $\pi, \pi^{*}$ Excited Singlet Alkene. Chem. Lett. 1982, 1045-1048.

(S4) Adam, W.; Oppenländer, T. 185-nm Photochemistry of Bicyclo[2.1.0]pentane and Cyclopentene. J. Am. Chem. Soc. 1985, 107, 3924-3928.

(S5) Spartan '14 Parallel Suite, version 1.1.8; Wavefunction Inc.: Irvine, CA, 2013.

(S6) Csonka, G. I.; Ruzsinszky, A.; Perdew, J. P. Estimation, Computation, and Experimental Correction of Molecular Zero-Point Vibrational Energies. J. Phys. Chem. A 2005, 109, 67796789.

(S7) Zhao, Y.; Truhlar, D. G. The M06 Suite of Density Functionals for Main Group Thermochemistry, Thermochemical Kinetics, Noncovalent Interactions, Excited States, and Transition Elements: Two New Functionals and Systematic Testing of Four M06-Class Functionals and 12 Other Functionals. Theor. Chem. Acc. 2008, 120, 215-241. 